\title{
Acute generalized exanthematous pustulosis associated with spider bite*
}

\author{
Laura de Mattos Milman ${ }^{1}$ \\ Paulo Ricardo Martins Souza ${ }^{1,2}$ \\ Deise Louise Bohn Rhoden ${ }^{1}$ \\ Gerson Vettorato ${ }^{1}$
}

\author{
Giana Paula Müller ${ }^{1}$ \\ Aline Barcellos Grill ${ }^{1}$ \\ Carlos Augusto Mello-da-Silva²
}

DOI: http://dx.doi.org/10.1590/abd1806-4841.20164045

\begin{abstract}
Acute generalized exanthematous pustulosis (AGEP) is an acute febrile rash, usually induced by drugs, which recently has been linked to spider bite. We report a case of a male patient, 48 years old, with an erythematous rash accompanied by fever and small non-follicular pustules. He reported previous pain in the buttock with the onset of a necrotic plaque. The lesion was compatible with spider bite of the genus Loxosceles. According to the EuroSCAR group instrument, the patient scored +10 indicating definite diagnosis of AGEP. As the patient had a compatible lesion and had no other triggers of AGEP, in an Loxosceles endemic area, the AGEP would be associated with spider bite, as described in other publications.
\end{abstract}

Keywords: Acute generalized exanthematous pustulosis; Arachnid vectors; Spider venoms

\section{INTRODUCTION}

Acute generalized exanthematous pustulosis (AGEP) is an acute febrile rash, characterized by numerous small non-follicular and sterile pustules on erythematous base. ${ }^{1-3}$

Over $90 \%$ of the cases are induced by drugs. Occasionally, AGEP is caused by infections and exposure to mercury and rarely it may be the consequence of a spider bite, as in the case reported. ${ }^{4,5}$

\section{CASE REPORT}

Male patient, 48 years old, from the metropolitan area of Porto Alegre (RS), sought medical attention due to disseminated erythematous lesions and fever for the past four days.

He reported a spider bite in the right buttock region. The spider was not found and the patient reported pain in the area while sleeping in his beach house. In 48 hours a violaceous spot appeared on the site.
On the third day he presented an erythematous eruption accompanied by several disseminated small non-follicular pustules, fever over $38^{\circ} \mathrm{C}$ and pruritus (Figure 1).

The gluteal lesion evolved, in four days, with the onset of a necrotic plaque, dry and well delimited. The edema and erythema adjacent to the lesion increased (Figure 2). The patient denied use of painkillers or other drugs. Since infection was suspected, cephalexin was prescribed.

He presented leukocytosis $(27,260$ leukocytes, with predominance of neutrophils) and increased transaminases (ALT 268; AST 56), GGT (366) and bilirubin (TB 2.5, IB 1.7, DB 0.8). As viral serology was negative and the diagnosis was AGEP, treatment was begun with prednisone ( $80 \mathrm{mg} /$ day).

The clinical picture progressed with diffuse desquamation and periorbital edema (Figure 3), as well as of hands and feet. On palms and plants, there was the onset of blisters with later desqua-

Received on 16.09.2014.

Approved by the Advisory Board and accepted for publication on 05.01.2015.

* Work performed at Dermatology Service of Hospital Complex of Santa Casa de Misericórdia de Porto Alegre.

Financial Support: None.

Conflict of Interest: None.

1 Complexo Hospitalar da Santa Casa de Misericórdia de Porto Alegre - Porto Alegre (RS), Brazil.

2 Pontifícia Universidade Católica do Rio Grande do Sul (PUC-RS) - Porto Alegre (RS), Brazil. 


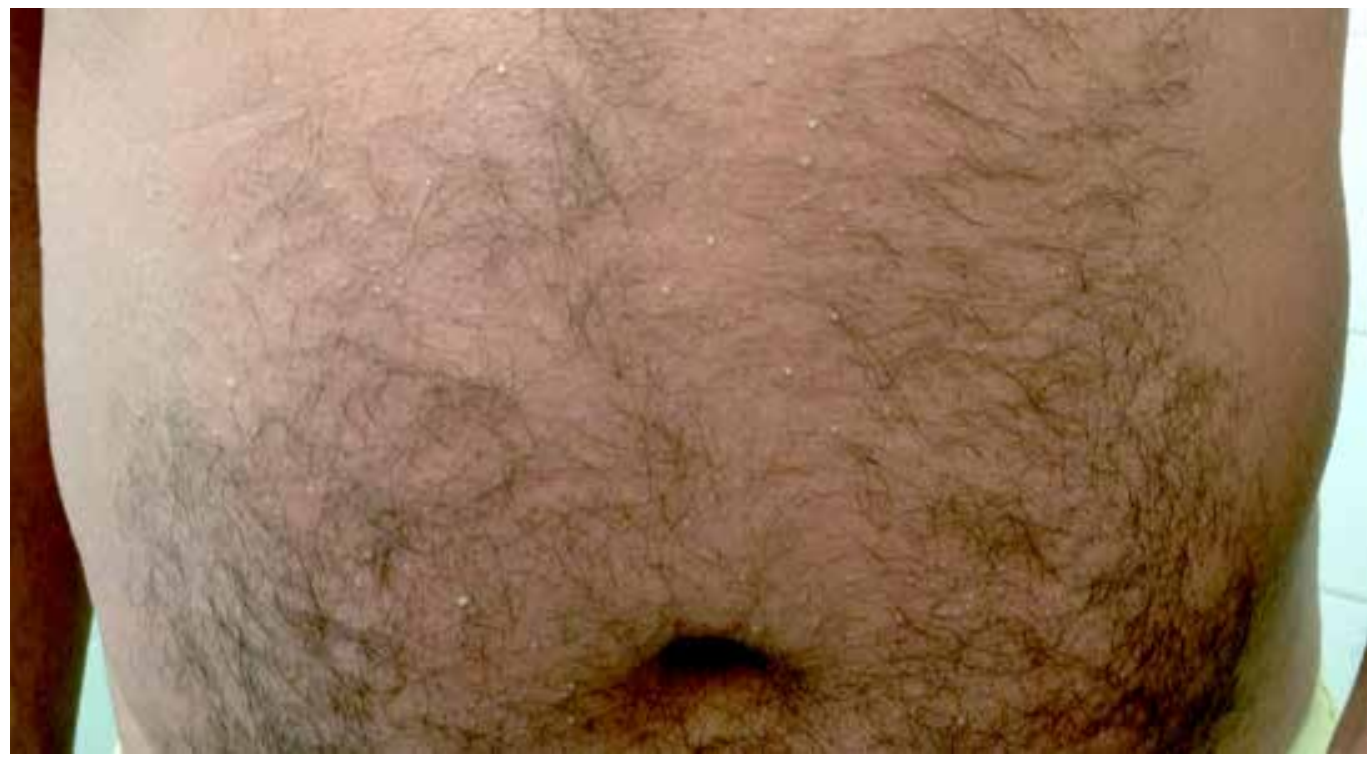

Figure 1:

Erythema and pustules on the abdomen

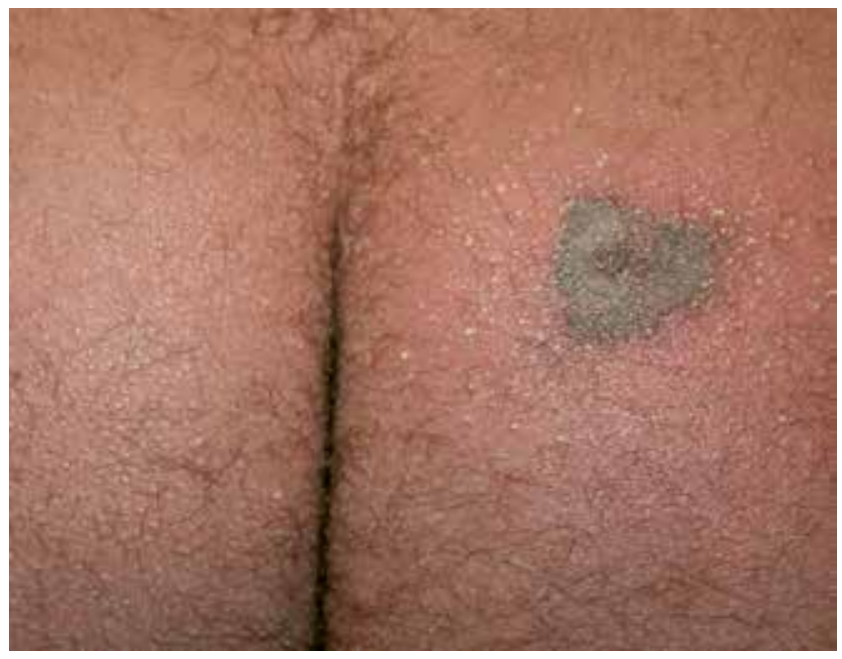

Figure 2: Necrotic plaque on the right buttock, surrounded by erythema and non-follicular pustules

mation. There was clinical and laboratorial improvement, which prompted gradual decrease of prednisone until its suspension. The buttock lesion evolved with detachment of the necrotic plaque and local ulcer.

Histopathology showed pustular dermatitis with neutrophilic vasculitis, focally purpuric, discrete edema in the dermal papillae and absence of leukocytoclasia (Figures 4 and 5).

\section{DISCUSSION}

The Loxosceles genus can be found all over Brazil, mainly in the state of Parana. They are small spiders, non-agressive, of nocturnal habits that bite when compressed against the human body. ${ }^{2,6}$ The diagnosis of loxoscelism is rarely based on the identification of the spider. Unless the patient captures the spider and brings it over for identification, the diagnosis is presumptive. In Brazil, 10,000 cases of Loxosceles bites are reported annually. ${ }^{6,7}$

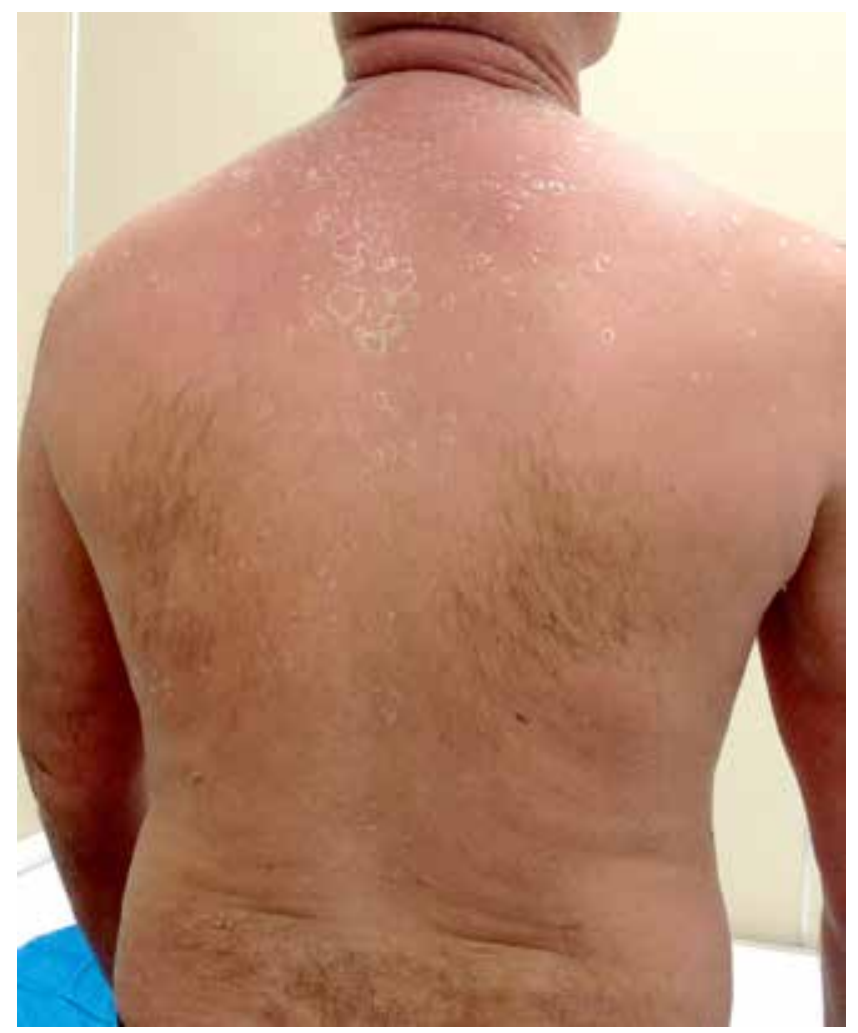

Figure 3: Desquamation of back

The bite is painless and causes local edema and erythema. There may be onset of ecchymotic areas mixed with paleness, blisters or necrosis. The lesion is prone to progress gravitationally, due to the action of hyaluronidase present in the venom. ${ }^{7}$

Systemic loxoscelism is rare and commonly associated with discreet symptoms, such as malaise and myalgia. There may also be mild hemolysis or, rarely, in the more severe forms, hemolytic anemia and acute renal lesion caused by severe hemolysis..$^{5,6}$ 

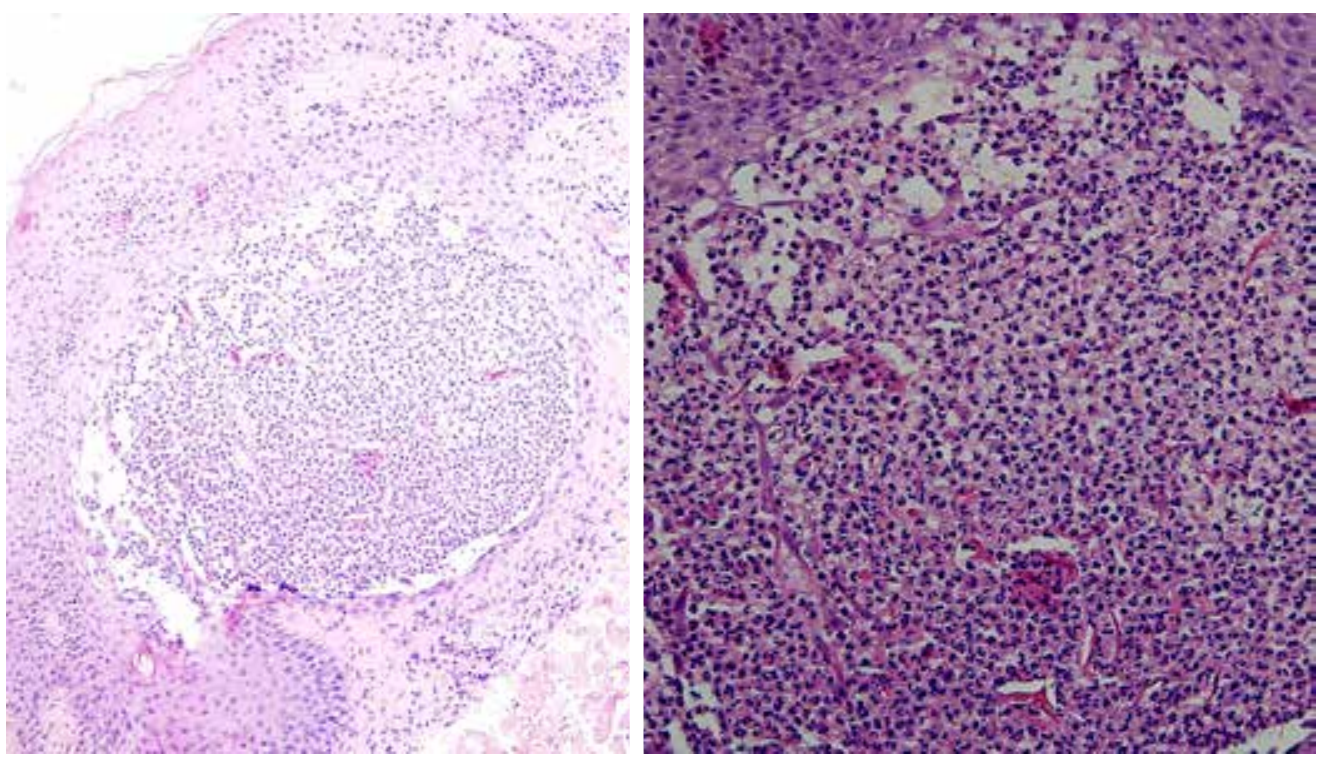

FIGURE 4:

Intraepidermal pustule and mild spongiosis. Discreet edema of dermal papillae and inflammatory perivascular infiltrate in the derm (hematoxilin-eosin, 40x to the left and $100 x$ to the right)

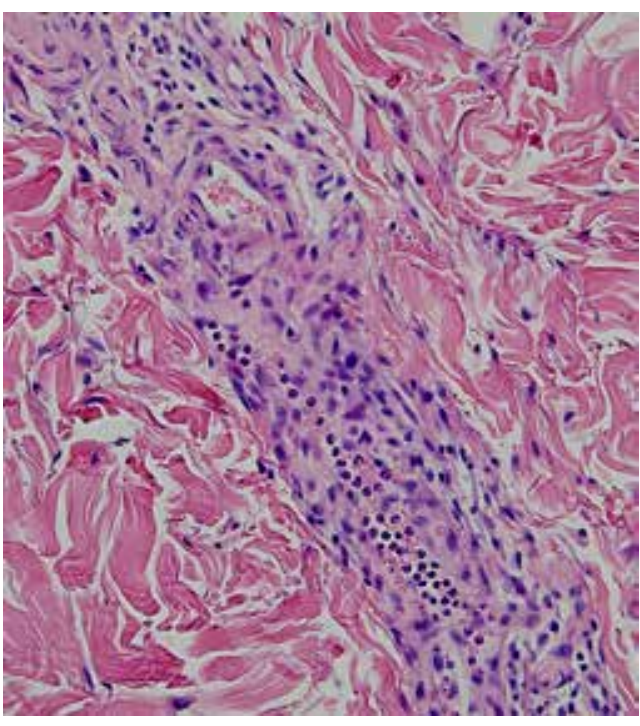

FIGURe 5:

Vessel in the derm with inflammatory perivascular infiltrate, predominantly neutrophilic with some lymphocytes (hematoxilin-eosin 100x)

In spite of the uniformity of the initial lesion being not characteristic, its evolution with detachment of the necrotic plaque and formation of ulcer is compatible with Loxosceles spider bite, especially because it is an endemic area. ${ }^{6,7}$

Exanthema following spider bite is uncommon. It occurs in 72 hours and is characterized as morbiliform or scarlatiniform rash. ${ }^{8}$ Palpable purple, pustular exanthema and even a mix of these two findings have been described. ${ }^{8}$

Recently, Loxosceles bite has been linked to AGEP. ${ }^{1-5}$ The triggering of AGEP after spider bite is rare, and its mechanism is not well understood.

In the pathogenesis of AGEP, IL-8 (interleukin-8) and GMCSF (Granulocyte-macrophage colony-stimulating factor) are implicated in polymorphonuclear recruiting for the epidermis. IL-8 is produced by keratinocytes and T-cells. The venom of this spider contains sphingomyelinase, which stimulates the liberation of cytokines, including a great amount of IL-8 and GM-CSF, which would trigger AGEP. ${ }^{2}$

The clinical picture of AGEP is characterized by the abrupt onset of erythema and edema in intertriginous areas or in the face, with craniocaudal dissemination and the arising of hundreds of small non-follicular and sterile pustules. It may be preceded or accompanied by high fever and pruritus. Pustules have an average duration of nine days, evolving with desquamation. Multiform erythema-type lesions, edema of face and hands, purpura, vesicles, blisters and involvement of mucosae are additional findings, some of them found in the case described. . $^{1,9,10}$

Histology may reveal spongiosis and subcorneal or intraepidermal pustules. There is edema in the dermal papillae, which may vary in intensity, neutrophils and eosinophils perivascular infiltrate and, sometimes, leukocytoclastic vasculitis. There may be focal necrosis of keratinocytes. ${ }^{1,9,10}$

In the complementary evaluation, there may be leukocytosis, with predominance of neutrophils and eosinophils, transitory loss of renal function and increased aminotransferases, findings that would justify some laboratorial changes found in the case described. ${ }^{1}$

According to EuroSCAR group's scoring system (European project dedicated to severe cutaneous adverse reactions), used in the identification of AGEP cases, the patient scored +10 , indicating definite diagnosis of AGEP (Table 1). ${ }^{9}$

As the patient had a lesion compatible with Loxosceles spider bite, without presenting other known AGEP triggers in a region where this spider is endemic, the conclusion was that AGEP would be associated with spider bite, as described in other publications. . $^{2,4,5,8}$

The increase of bilirubins may be attributed to mild hemolysis, frequently found in loxoscelism. ${ }^{6}$

There is a report that histologically characterizes the exanthema after spider bite not linked to AGEP as necrotizing vasculitis, similar to the one observed in the bite area, but without epidermal 
TABLE 1: AGEP score of patient determined by the use of criteria from EuroSCAR study group

\begin{tabular}{|c|c|c|}
\hline Criteria & Description & Score \\
\hline \multicolumn{3}{|l|}{ Morphology } \\
\hline Pustules & Typical, non-follicular and sterile & +2 \\
\hline Erythema & Typical, diffuse & +2 \\
\hline Distribution & Compatible, trunk and members & +1 \\
\hline Desquamation post-pustulation & Yes & +1 \\
\hline Additional findings & No & \\
\hline \multicolumn{3}{|l|}{ Course } \\
\hline Mucosal involvement & No & 0 \\
\hline Acute start (< 10 days) & Yes & 0 \\
\hline Resolution $<15$ days & Yes & 0 \\
\hline Fever $\left(\geq 38^{\circ} \mathrm{C}\right)$ & Yes & +1 \\
\hline Polymorphonuclear $(\geq 7.000)$ & Yes & +1 \\
\hline \multicolumn{3}{|l|}{ Histopathology } \\
\hline Biopsy of skin & $\begin{array}{l}\text { Intraepidermal pustule with dermal edema, } \\
\text { perivascular neutrophilic infiltrate }\end{array}$ & +2 \\
\hline TOTAL SCORE & & +10 \\
\hline
\end{tabular}

Interpretation according to final score: $\leq$ : absence of AGEP; 1-4: possible AGEP; 5-7: probable AGEP; 8-12: AGEP as certain diagnosis

necrosis. ${ }^{8}$ These alterations were not found in our patient, whose anatomopathological results were compatible with AGEP.

The prognosis of AGEP is good when triggered by medication. ${ }^{1}$ Due to few reports of cases linked to spider bite, it is not clear if there is alteration of the prognostic.

Other reports had their etiological diagnosis made difficult by the simultaneous and early use of antibiotics. In this report, as the patient started their use when he already presented lesions with
AGEP characteristics, the antibiotic did not seem relevant in triggering the pathology.

Treatment is symptomatic. ${ }^{1}$ A short course of systemic corticoid may be considered in severe cases, but usually it is not necessary, due to the self-limiting character of lesions. ${ }^{3,10}$

This report of AGEP associated with spider bite aims to point out to this rare triggering factor in Brazil, where incidents by Loxosceles bites are frequent.]

\section{REFERENCES}

1. Razera F, Olm GS, Bonamigo RR. Neutrophilic dermatoses: part II. An Bras Dermatol. 2011;86:195-209.

2. Makris M, Spanoudaki N, Giannoula F, Chliva C, Antoniadou A, Kalogeromitros D. Acute generalized exanthematous pustulosis (AGEP) triggered by a spider bite. Allergol Int. 2009;58:301-3.

3. Leclair MA, Maynard B, St-Pierre C. Acute generalized exanthematous pustulosis with severe organ dysfunction. CMAJ. 2009;181:393-6.

4. Davidovici BB, Pavel D, Cagnano E, Rozenman D, Halevy S; EuroSCAR; et al. Acute generalized exanthematous pustulosis following a spider bite: report of 3 cases. J Am Acad Dermatol. 2006;55:525-9.

5. Lane L, McCoppin HH, Dyer J. Acute generalized exanthematous pustulosis and Coombs-positive hemolytic anemia in a child following Loxosceles reclusa envenomation Pediatr Dermatol. 2011;28:685-8.

6. Malaque CM, Santoro ML, Cardoso JL, Conde MR, Novaes CT, Risk JY, et al. Clinical Picture and laboratorial evaluation in human loxoscelism. Toxicon. 2011;58:664-71.

7. Cardoso JLC, França FOS, Wen, FH, Malaque CMS, Haddad V. Animais peçonhentos no Brasil. 2 ed. São Paulo: Editora Sarvier; 2009. p. 182-3.

8. Robb CW, Hayes BB, Boyd AS. Generalized vasculitic exanthema following Loxosceles recluse envenomation. J Cutan Pathol. 2007;34:513-4.
9. Fernando SL. Acute generalised exanthematous pustulosis. Australas J Dermatol. 2012;53:87-92.

10. Sidoroff A, Halevy S, Bavinck JN, Vaillant L, Roujeau JC. Acute generalized exanthematous pustulosis (AGEP) - A clinical reaction pattern. J Cutan Pathol. 2001;28:113-9.
MAILING ADDRESS:
Laura de Mattos Milman
Rua Professor Annes Dias, 295
Centro Histórico
90020-090 - Porto Alegre - RS
Brazil
E-mail:Immilman@terra.com.br

How to cite this article: Milman LM, Müller GP, Souza PRM, Grill AB, Rhoden DLB, Mello-da-Silva CA, Vettorato G. Acute generalized exanthematous pustulosis associated with spider bite. An Bras Dermatol. 2016;91(4):524-7. 